\title{
Variation of the supernumerary head of the biceps brachii muscle: two case reports and literature review
}

\author{
Barış Özgür Dönmez, Bahadır Murat Demirel, Umut Özsoy, Arzu Ütük, Levent Sarıkcığlu \\ Department of Anatomy, Faculty of Medicine, Akdeniz University, Antalya, Turkey
}

\begin{abstract}
Supernumerary heads of the biceps brachii muscle have been widely studied regarding their origin, insertion, size, innervation and racial differences. The most frequent variation of the biceps brachii is its supernumerary heads. During our routine dissection studies, we encountered supernumerary head of the biceps brachii muscle on two cadavers. Additionally, the supernumerary heads had abnormal attachments. We think that such variations should be kept in mind during surgical and diagnostic procedures.
\end{abstract}

Key words: biceps brachii muscle; supernumerary head; variation

Anatomy 2010; 4: 63-66, (c) 2010 TSACA

\section{Introduction}

The biceps brachii muscle is typically described as originating with a long head from the supraglenoid tubercle and with a short head from the coracoid process. The two heads then join to form a common tendon, attaching on the radial tuberosity. In addition, the tendon contributes to the bicipital aponeurosis, an aponeurotic expansion continued into the antebrachial fascia. $^{1,2}$

Supernumerary heads of the biceps brachii muscle are not rare and have been well documented in the literature. ${ }^{3}$ Testut ${ }^{4,5}$ described the biceps brachii muscle as one of the muscles with very frequent anatomic variations. It is estimated that $9-22 \%$ of the people has a supernumerary head. ${ }^{6,7}$ A supernumerary head of the biceps brachii muscle may extend from the superomedial part of the brachialis muscle to the bicipital aponeurosis, or may originate from the lateral humeral aspect of the intertubercular groove. ${ }^{3}$ Two cases with a supernumerary head of the biceps brachii originating from the lips of the intertubercular groove were encountered during our dissection studies. The cases were presented and discussed along with the relevant literature.

\section{Case Report}

During our routine dissection studies we encountered two cases with variant formation of the supernumerary head of the biceps brachii muscle.

\section{Case 1}

The case was a 57-year-old male cadaver. The supernumerary head was a bulky muscle belly and originated from the medial lip of the intertubercular groove (Figure 1a). Then it laid downward just medial to the tendon of the long head and conjoined to the fibers of the short head at the middle third of the arm. The short and 
supernumerary heads united to form a great part of the biceps brachii muscle. The long head originated from the normal attachment site and located lateral to the short and supernumerary heads. Tendon of the long head united to the tendon of the other two heads. The attachment of the common tendon was normal in every aspect.

\section{Case 2}

The case was a 45-year-old male cadaver. The supernumerary head was a bulky muscle belly and originated from the lateral lip of the intertubercular groove (Figure 1b). When it was encountered, insertion of the pectoralis major muscle had already been cut during dissections performed by our students. Then it laid downward just lateral to the tendon of the long head and conjoined to the fibers of the short head at the middle third of the arm. Origination and progress of the short head was normal in every aspect. It was just main difference that short and supernumerary heads united to form a great part of the biceps brachii muscle.

The long head of the biceps brachii muscle originated from the supraglenoid tubercle and laid in the intertubercular groove. It was in a vertical position and covered by the two conjoined heads (short and supernumerary heads). At first sight, it was difficult to see the muscle fibers of the long head, splitting of interval between the short and supernumerary heads revealed the muscle

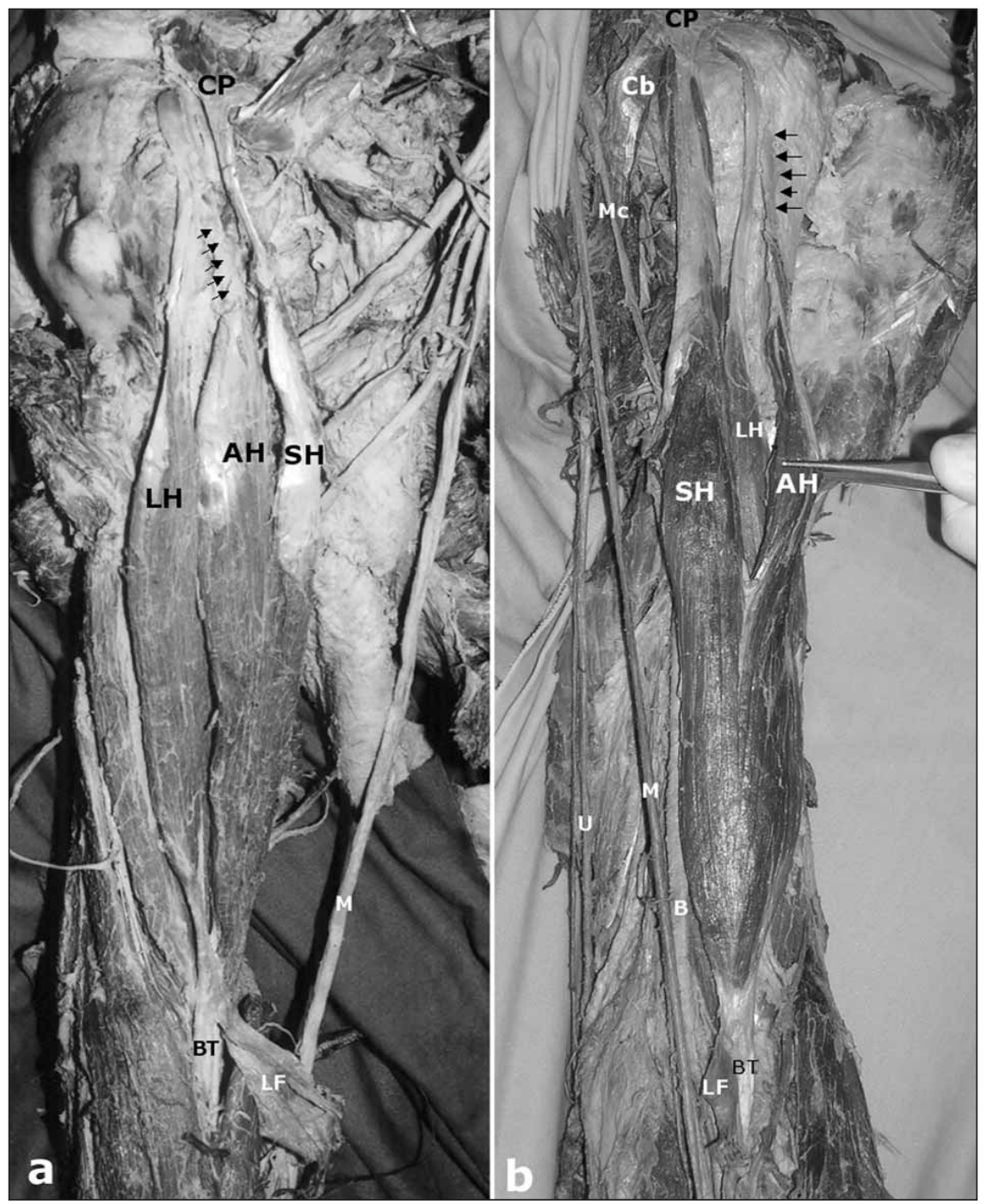

Figure 1. Photographs of the cases showing supernumerary head of the biceps brachii muscle.

a: Case 1 (Right side). AH: accessory head of biceps brachii muscle; $\mathrm{BT}$ : tendon of the biceps brachii muscle; CP: coracoid process of scapula; LF: bicipital aponeurosis (lacertus fibrosus); LH: long head of biceps brachii muscle; M: median nerve; SH: short head of biceps brachii muscle; Arrows: tendon of the supernumerary head of biceps brachii muscle.

b: Case 1 (Left side). AH: accessory head of biceps brachii muscle; B: brachial artery, BT: tendon of the biceps brachii muscle; $\mathrm{Cb}$ : coracobrachialis muscle; CP: coracoid process of scapula; LF: bicipital aponeurosis (lacertus fibrosus); LH: long head of biceps brachii muscle; M: median nerve, Mc: musculocutaneus nerve; $\mathrm{SH}$ : short head of biceps brachii muscle, U: ulnar nerve; Arrows: tendon of the supernumerary head of biceps brachii muscle. 
belly. The long head was fully separated from the conjoined heads. The musculocutaneous nerve and nutrient branches of the brachialis artery situated between the long head and conjoined heads. The long head united to the most distal fibers of the supernumerary head and contributed to the common tendon of the biceps brachii muscle. The common tendon inserted on the radial tuberosity and an aponeurotic expansion, bicipital aponeurosis, continued into the antebrachial fascia of the forearm.

In both cases, the biceps brachii muscle and its supernumerary head were innervated by branches of the musculocutaneous nerve and were supplied with blood by small muscular tributary of the brachial artery.

\section{Discussion}

Supernumerary heads of the biceps brachii muscle have been widely studied regarding their origin, insertion, size, innervation and racial differences. ${ }^{1,3,7-11}$ Supernumerary heads of the biceps brachii muscle have been described as part of either a three, four, or fiveheaded biceps brachii muscle. ${ }^{2,6,8,12-20}$ Recently, Rodriguez-Niedenfuhr et al. ${ }^{1}$ studied on a series of 350 arms and classified the supernumerary heads of the biceps brachii into three different types: superior, inferomedial, and infero-lateral humeral head. They found five cases $(1.5 \%)$ with supernumerary head originated from the surface of the humerus between the lesser tubercle and the attachments of the coracobrachialis and brachialis muscles and fused with the muscular fibers of the short head of the biceps brachii muscle at its union with the long head. Additionally, Nayak and Krishnamurthy ${ }^{18}$ reported that supernumerary head of the biceps brachii muscle and long head originated from the deltoid and pectoralis major muscles. Schoenleber and Spinner ${ }^{17}$ found that supernumerary head of the biceps brachii and long head originated from the deltoid muscle itself.

The presence of supernumerary heads of the biceps brachii muscle has been associated with variations of the surrounding muscles. El-Naggar and Zahir ${ }^{15}$ described that a two bellies of the coracobrachialis muscle associat- ed with a third head of the biceps brachii muscle, although the coracobrachialis muscle was found to have a normal origin, short head of the biceps brachii muscle had separate bellies.

The presence of supernumerary heads of the biceps brachii muscle has been associated with variations of the musculocutaneous nerve. ${ }^{6,14}$ The musculocutaneous nerve or its connection with the median nerve usually passed deep to the supernumerary head but may also pass superficial to it or have no relationship to it at all., Besides, there was no variation in the origin and distribution of the musculocutaneous nerve, a supernumerary head covered to the customary long head, as observed in our case, contradicts the theory of Hyrtl, ${ }^{21}$ who suggested that the presence of supernumerary medial heads was due to the musculocutaneous nerve piercing the brachialis muscle and producing a supernumerary separate head.

Embryologically, during the fifth week of development, mesoderm invades the upper limp bud to further condense into ventral and dorsal muscle masses. The triceps and biceps musculature is derived from the dorsal and ventral muscle masses of the upper limb bud, respectively. It would be during this period of development that accessory muscles may have formed. ${ }^{16}$ Shah and Shah ${ }^{22}$ reported a unique case with a bilateral quadricipital biceps brachii muscle comprised by long, short, third (humeral) heads, and a fourth (capsular) head. For fourth head, they suggest that it might be a portion of the embryonic long head, which had failed to become intracapsular.

Variations of the heads of the biceps brachii muscle have clinical importance. ${ }^{1,2}$ Supernumerary heads may confuse surgeons during shoulder operations ${ }^{1,23}$ or cause compression of neurovascular structures. ${ }^{1,2}$ Therefore, surgeons should be aware of this anatomical variation in surgical procedures. ${ }^{16,19}$

\section{Acknowledgement}

We thank Mr. Necati Sağıroğlu, Mr. Hüseyin Gezer and Mr. Hasan Savc1lı for their technical assistance. 


\section{References}

1. Rodriguez-Niedenfuhr M, Vazquez T, Choi D, Parkin I, Sanudo JR. Supernumerary humeral heads of the biceps brachii muscle revisited. Clin Anat 2003; 16: 197-203.

2. Abu-Hijleh MF. Three-headed biceps brachii muscle associated with duplicated musculocutaneous nerve. Clin Anat 2005; 18: 3769.

3. Bergman R, Thompson SA, Afifi AK. Catalog of human anatomical variation. Baltimore: Urban Schwarzenberg; 1985.

4. Testut L. Les anomalies musculaires chez l'homme. Paris: Masson; 1884.

5. Testut L. Signification anatomique du chef huméral du muscle biceps. Bull Mem Soc Anthropol Paris 1883; 6: 238-45 (cited by Rodriguez-Niedenfuhr et al.).

6. Kosugi K, Shibata S, Yamashita H. Supernumerary head of biceps brachii and branching pattern of the musculocutaneus nerve in Japanese. Surg Radiol Anat 1992; 14: 175-85.

7. Santo Neto H, Camilli JA, Andrade JC, Meciano Filho J, Marques MJ. On the incidence of the biceps brachii third head in Brazilian white and blacks. Ann Anat 1998; 180: 69-71.

8. Asvat R, Candler P, Sarmiento EE. High incidence of the third head of biceps brachii in South African populations. F Anat 1993; 182(Pt 1): 101-4.

9. Greig HW, Anson BJ, Budinger JM. Variations in the form and attachments of the biceps brachii muscle. Q Bull Northwest Univ Med Sch 1952; 26: 241-4.

10. Khaledpour C. Über Anomalien des M. biceps brachii. Anat Anz 1985; 158: 79-85.

11. Kopuz C, Sancak B, Ozbenli S. On the incidence of third head of biceps brachii in Turkish neonates and adults. Kaibogaku Zasshi 1999; 74: 301-5.
12. Şimşek C, Ertem AD, Ozan H, Akkın SM. M. biceps brachii'nin baş fazlalığı. Cerrahpaşa Tip Fakiiltesi Dergisi (Istanbul) 1994; 25: 511-5.

13. Swieter MG, Carmichael SW. Bilateral three-headed biceps brachii muscles. Anat Anz 1980; 148: 346-9.

14. Nakatani T, Tanaka S, Mizukami S. Bilateral four-headed biceps brachii muscles: the median nerve and brachial artery passing through a tunnel formed by a muscle slip from the accessory head. Clin Anat 1998; 11: 209-12.

15. El-Naggar MM, Zahir FI. Two bellies of the coracobrachialis muscle associated with a third head of the biceps brachii muscle. Clin Anat 2001; 14: 379-82.

16. Nayak SR, Krishnamurthy A, Kumar M, Prabhu LV, Saralaya V, Thomas MM. Four-headed biceps and triceps brachii muscles, with neurovascular variation. Anat Sci Int 2008; 83: 107-11.

17. Schoenleber SJ, Spinner RJ. An unusual variant of the biceps brachii. Clin Anat 2006; 19: 702-703.

18. Nayak SR, Krishnamurthy A. An unusual supernumerary head of biceps brachii muscle. Clin Anat 2008; 21: 788-9.

19. Rai R, Ranade AV, Prabhu LV, Pai MM, Prakash. Third head of biceps brachii in an Indian population. Singapore Med $\mathcal{F} 2007$; 48: 929-31.

20. Sargon MF, Tuncali D, Celik HH. An unusual origin for the accessory head of biceps brachii muscle. Clin Anat 1996; 9: 160-2.

21. Hyrtl J. Handbuch der Topographischen Anatomie und ihrer praktisch medizinisch-chirurgischen Anwendungen. 6th ed. Wien: Wilhelm Braumüller; 1871.

22. Shah MA, Shah M. Quadricipital m. biceps brachii. J Anat 1946; 80: 54 .

23. Warner JJ, Paletta GA, Warren RF. Accessory head of the biceps brachii. Case report demonstrating clinical relevance. Clin Orthop Relat Res 1992: 179-81.

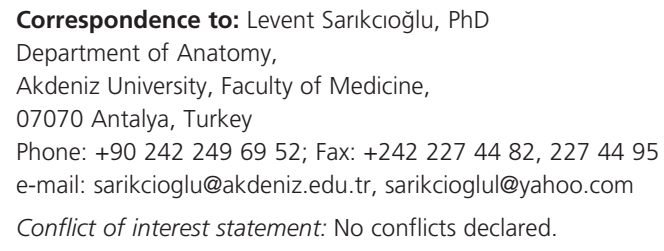

